\title{
A ESCRITA NATIVA COMO INSTRUMENTO DE PRESERVAÇÃO LINGUÍSTICA
}

\author{
Gean Nunes DAMULAKIS ID \\ Universidade Federal do Rio de Janeiro (UFRJ)
}

RESUMO

Apresentamos aqui um relato de atividades em um curso sobre produção textual para professores indígenas em uma aldeia Kaingang. O trabalho desenvolvido buscou despertar a valorização da escrita da língua nativa, com vistas para o incremento da paisagem linguística em aldeia Kaingang. Os indígenas mostraram interesse pela proposta de uso de placas e letreiros na comunidade. O aumento da paisagem linguística suscita discussões sobre a língua escrita, além de aumentar a visibilidade da língua.

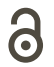

OPEN ACCESS

EDITORES

- Marcus Maia (UFRJ)

- Bruna Franchetto (UFRJ)

\section{AVALIADORES}

- Wilmar D'Angelis (UNICAMP)

- Marcia Nascimento (UFRJ)

DATAS

- Recebido: 31/05/2020

- Aceito: 07/10/2020

- Publicado: 28/12/2020

\section{ABSTRACT}

Here we present a brief report of activities in a text production course for indigenous teachers in a Kaingang village. The work developed proposed to awaken the appreciation of native language writing, in order to increase the linguistic landscape in the village. The indigenous people showed interest in the proposal to use signs in the community. The increase in the linguistic landscape raises discussions about the written language, in addition to increasing the visibility of the language.

\section{PALAVRAS-CHAVE}

Kaingang; Escrita Indígena; Ortografia; Paisagem Linguística.

KEYWORDS

Kaingang; Indigenous Writing; Orthography; Linguistic Landscape. 


\section{INTRODUÇÃO}

Este trabalho apresenta um relato de experiência referente ao uso da escrita em língua Kaingang, na escola e na aldeia indígena. A experiência se deu no desenrolar de um projeto de extensão intitulado "Produção Textual para Professores Indígenas", que buscou oferecer, para professores indígenas, algumas reflexões sobre a prática de escrita em ambiente bilíngue. O recorte que apresentamos aqui são reflexões acerca da possibilidade de considerar a modalidade escrita da língua indígena como instrumento auxiliar para a preservação da língua. O curso pensou em estratégias para que o uso a escrita da língua Kaingang fosse estimulado, sobretudo na escola, mas também em outras instâncias na aldeia, mais precisamente na T.I. Nonoai, no norte do Rio Grande do Sul, onde o curso foi realizado. A língua Kaingang é falada nos três estados do sul do Brasil (PR, SC e RS) e no oeste de São Paulo.

Para que pudéssemos pensar na ideia de abranger o uso da língua na aldeia, discutimos aqui a noção de paisagem linguística e a de letramento. Sabemos que o indígena, ao sair da aldeia, encontra uma situação em que apenas a língua portuguesa (e inglês também) encontra lugar na paisagem; mais uma vez, a relação entre as línguas portuguesa e indígena se mostra assimétrica, sendo o português elevado à categoria de língua que pode ser representada nos meios, à exclusão da língua indígena; por outro lado, a escrita tem sido uma ferramenta pleiteada por várias comunidades, por colocar a língua, num alcance simbólico, no mesmo patamar da "língua do branco". Mas é importante que essa ferramenta seja posta em prática1.

Embora boa parte da comunidade seja bilíngue, e para parte desses indivíduos a alfabetização em ambas as línguas alcance objetivos satisfatórios, o uso da modalidade escrita da língua costuma ser muito limitado, quase sempre voltado apenas para o ambiente escolar. Quase sempre a escrita está restrita a materiais didáticos. Levar os indígenas a refletir, portanto, sobre instâncias de uso da língua escrita, com a possibilidade de consequente acréscimo no nível de letramento foi um dos objetivos do curso oferecido para os professores indígenas.

1 Um dos usos mais recorrentes recentemente tem sido os meios digitais: alguns indígenas têm adotado o uso dessa ferramenta nos meios digitais, como em posts e comentários no Facebook e mensagens via WhatsApp. Esses usos serão objetos de uma segunda fase do curso. 


\section{OBJETIVOS E METODOLOGIA}

O objetivo geral deste relato é expor experiências no âmbito do Curso de Extensão "Produção Textual para Professores Indígenas", realizado em 2016 e 2018, com professores Kaingang, na T.I. Nonoai, no norte do Rio Grande do Sul. Como objetivos específicos são: 1) mostrar como o estímulo do domínio de determinados gêneros, bem como o uso do Kaingang nesses gêneros, sempre que possível (como traduções ou registros de gêneros orais), podem oferecer ampliação de contextos de uso da escrita da língua; 2) refletir sobre o uso da escrita da língua indígena (ou língua indígena escrita) e suas possíveis instâncias de uso, mais particularmente com o intuito de aumentar a visibilidade da língua escrita.

O curso ocorreu em uma escola indígena na TI Nonoai, no município de Gramado dos Loureiros, RS. Foram propostas de atividades para esses professores, no intuito de trabaIhar não apenas a reflexão sobre os gêneros textuais, como refletir sobre o trabalho que esses professores poderiam desenvolver em suas salas de aula. Além disso, tendo como ponto de partida a materialização desses gêneros em português, houve a preocupação de pensar na versão desses textos para a língua Kaingáng. Dessa forma, procuramos não perder o foco no objetivo de munir os professores de teoria e de potencial uso dessa teoria para a prática em sala de aula, quer ela ocorra nas aulas de língua portuguesa para indígenas, quer nas de língua indígena.

Houve também a preocupação em pensar a escola indígena bilíngue e o trabalho com o uso da escrita. Houve especial atenção, neste relato, aos gêneros placa e letreiro, devido ao vínculo desses gêneros com o conceito de paisagem linguística, defendida aqui como um recurso importante, embora não imprescindível, para a preservação da língua.

\section{LETRAMENTO E ESCRITA PARA OS POVOS INDÍGENAS}

É preciso sempre reafirmar, de antemão, a importância da oralidade para a manutenção de uma língua, de maneira que manter as instâncias de uso da língua falada é uma condição imprescindível para que a língua consiga sobreviver. Dessa forma, a escrita vem como uma ferramenta auxiliar nessa luta, agindo basicamente em duas frentes: 1) servindo de maneira de registrar tradições orais, mais particularmente nos casos em que essas tradições tendem a desaparecer; 2) mais especificamente no caso dos povos indígenas, a escrita na língua atua como um fator simbólico, uma vez que coloca a língua em suportes que antes apenas estampava a língua politicamente dominante. Sobre esse segundo ponto, D’Angelis (2012, p. 188) afirma que 
Esse fato [veiculação em espaços antes exclusivos da língua majoritária], por si só, tem enorme impacto na representação que fazem, os próprios falantes nativos (com especial atenção, à formação das crianças), a respeito de sua línguas, de seus conhecimentos e de si mesmos.

Além disso, sabe-se que a escolarização, processo intimamente ligado à adoção da escrita e ao acréscimo de letramento, constituiu (e ainda pode se constituir) instrumento de erosão linguística para povos nativos (D’ANGELIS, 2007, 2012; FRANCHETTO, 2008; entre outros). De todo modo, a escrita na língua indígena pode se tornar uma ferramenta importante, sobretudo se associada a um letramento que incorpore as práticas bilíngues dos indígenas. A situação ambígua da escola, entre favorecimento da perda linguística e promoção da escrita - tendo esta efeitos positivos para a preservação da língua - foi postulada por D’Angelis (2012, p. 175) da seguinte maneira:

\footnotetext{
A tese central que se propõe, aqui, e cujas causas se pretende analisar, é que o ensino escolar - seja no formato do programa de bilingüismo de substituição dos anos 70 , seja no formato recente de "escolas indígenas" que pretendem promover um "ensino diferenciado" - efetivamente tem contribuído para a perda de vitalidade das línguas minoritárias nas comunidades indígenas do Brasil Meridional. Em contrapartida - e em aparente paradoxo - defende-se que o desenvolvimento da escrita em língua indígena (que só costuma ocorrer ligado a programas de ensino escolar) pode ser um dos instrumentos mais importantes de vitalização e fortalecimento dessas línguas.
}

Segundo Soares (1998), letramento é "o estado ou condição que adquire um grupo social ou um indivíduo como consequência de ter-se apropriado da escrita e de suas práticas sociais". Para Kleiman (2008), letramento pode ser entendido como o conjunto de "das práticas relacionadas com a escrita em toda atividade da vida social". É preciso pensar em quais seriam as práticas de escrita que seriam eleitas pelos indígenas para essa questão. Duas possibilidades principais, que devem ser pensadas com ressalvas, são: 1) sugerir que as práticas de escrita em português sejam substituídas pelo Kaingang; 2) propor que práticas de oralidade na língua indígena sejam substituídas por práticas de escrita.

O principal problema da primeira proposição seria uma existência sem funcionalidade, a menos que a prática seja reincorporada, de forma significativa. Após discussão sobre as características do gênero ata, por exemplo, propusemos a redação em grupo de redações de ata na língua indígena, sobre temas discutidos nos respectivos grupos. Sobre seu uso na vida real, sugerimos que a ata poderia registrar decisões em reuniões, que não são muito raras entre os indígenas. Entretanto, salientamos que, nesse caso, esse documento apenas poderia ser usado para uma reunião em que apenas indígenas estivessem presentes e/ou no caso em que a reunião tivesse transcorrido em Kaingang. Quanto à segunda possibilidade acima, é necessário que o registro de gêneros orais, como piadas ou narrativas diversas, por exemplo, tenha alguma função específica, como a de garantir a preservação da narrativa, por exemplo.

Dessa forma, estimular o letramento em uma língua indígena, numa comunidade indígena, equivale a tornar a escrita como elemento integrante de determinadas práticas 
sociais. Uma das sugestões, não necessariamente trabalhadas em sala de aula, mas previstas para uma segunda fase do curso, seria pensar nas ferramentas tecnológicas e o uso da língua indígena por esses meios.

O Curso de Extensão desenvolvido tentou focar em propostas de instâncias de uso da língua indígena, pensando em meios para a circulação da língua escrita:

a) Aumentar a circulação da língua escrita (através de novos gêneros e da versão para escrita de gêneros (orais) existentes)

b) Atas, piadas, notícias (confecção de jornais na escola, por exemplo)

c) Localização (através de uso dos gêneros placa e letreiro, por exemplo)

As atividades se dividiram em dois tipos principais: as de incremento de letramento e as de incremento de paisagem linguística. A vinculação entre paisagem linguística e letramento, entretanto, é natural: saber localizar-se através de placas e letreiros é uma das possíveis e desejáveis consequências do letramento. As atividades do curso foram: gêneros/instâncias, produção de glossários temáticos (referentes à pesca, à agricultura, sobretudo fornecido pelos mais velhos); sugestões de jornalzinho na escola; registros de piadas e atas em Kaingang; redação de notícias em Kaingang; confecção de placas e letreiros em Kaingang. Quanto à última atividade proposta, pensou-se justamente como meio de incrementar a paisagem linguística.

\section{DESDOBRAMENTOS}

Uma das discussões, com impactos mais importantes para o recorte deste relato, foi referente ao uso da língua escrita na comunidade, de maneira que o uso de placas e sinalizadores pudessem garantir a individualidade linguística do ambiente. Nesse contexto, embora não tenha sido abordado nesses termos, faz-se necessário pensar no conceito de paisagem linguística, que pode ser definida como "visibilidade e saliência de línguas em letreiros (placas) públicos e comerciais em um dado território ou região” (LANDRY; BOURHIS, 1997). Se, por um lado, a língua se mantém, como dissemos antes, pela oralidade, de forma que sua 'audibilidade' está garantida, incentivar os veículos de paisagem linguística equivale a aumentar a 'visibilidade' da língua nos ambientes de circulação geral.

Uma visão mais alargada desse conceito inclui a exibição de língua em propagandas, lojas, restaurantes, camisetas, bonés, sacolas, nomes de ruas e de locais etc. Pensando nesse incremento, sugerimos aos cursistas que se dividissem em grupos e pensassem em 
como poderia ser a Aldeia, se placas e letreiros poderiam ser colocados na comunidade de forma a aumentar a visibilidade da língua.

Na Aldeia, basicamente é possível ver a língua escrita nos pórticos de entrada e de saída: Kamũ Há Hanra “Bem-vindo" e Mũ Há Hanra "Boa viagem!". Na escola, poucas eram as ocorrências da língua escrita. Nesse contexto, é perfeitamente possível delimitar placas referentes aos espaços (sala 1, sala 2, refeitório, banheiro, ginásio de esportes etc.), exposição de cartazes, avisos e etiquetagem de mobiliário (bebedouro, quadro, mesa etc.) $)^{2}$. Placas que indiquem a direção de pontos de referência (como escolas, postos de saúde, localidades etc.) e letreiros para indicar essas instituições podem aumentar a participação da língua indígena na paisagem linguística na comunidade.

\section{ATIVIDADE PROPOSTA}

Embora tenhamos, no âmbito do curso, proposto outras atividades de produção textual, em ambas as línguas, nos deteremos, neste relato, à atividade de incremento da paisagem linguística. Solicitamos aos cursistas que apresentassem proposta de mapeamento da aldeia, pensando em como o ambiente de circulação pudesse ser enriquecido com placas e letreiros em língua Kaingang, de maneira que isso garantisse a individualidade da comunidade em relação ao entorno. Nesse momento, apenas placas em Kaingang foram solicitadas. É possível pensar também, em caso de implementação do projeto na vida real, em placas e letreiros bilíngues, uma vez que a maior parte dos indivíduos da comunidade são bilíngues e bilíngues são as escolas, como foi o caso de algumas ocorrências. Abaixo, apresentamos (trechos de) alguns dos projetos apresentados.

2 Como observado pelo parecerista, a etiquetagem de mobiliário é muito antiquada e pouco producente. A colocação de etiquetas bilíngues, entretanto, me parece uma prática com maior informatividade que a etiquetagem monolíngue, sobretudo por conta do fato de alguns dos alunos, conforme constatamos, não serem falantes nativos da língua Kaingang. 


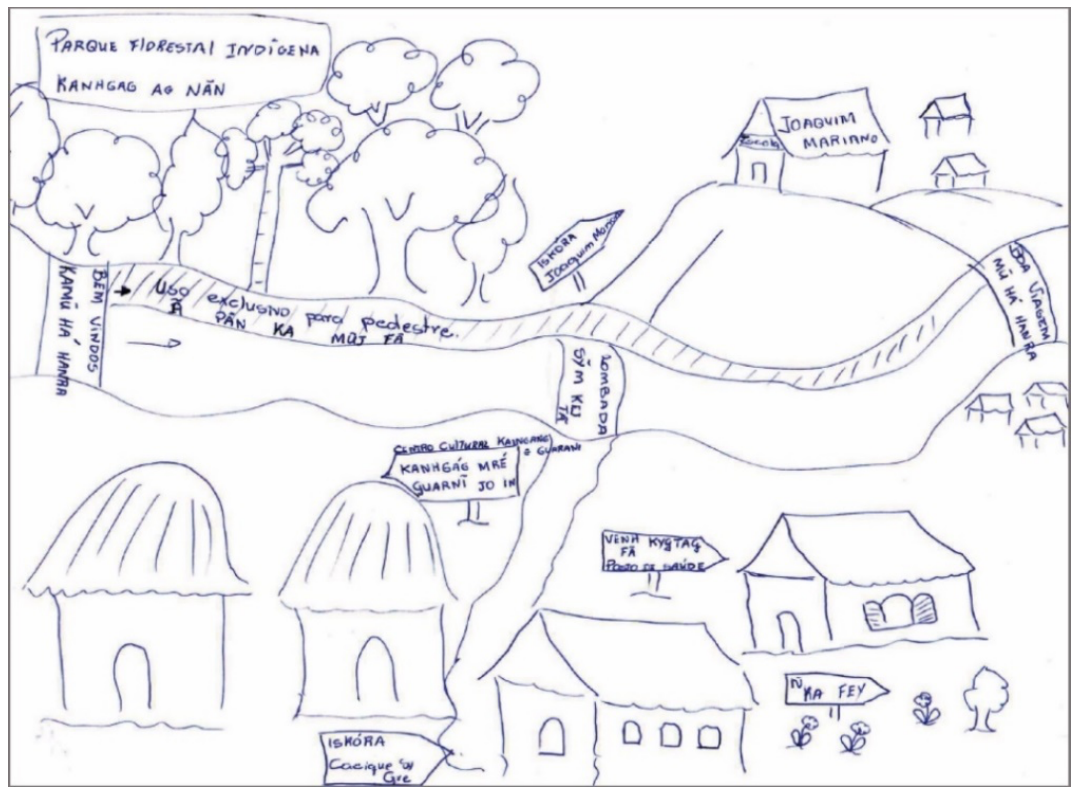

Figura 1. Mapa 1: Trabalho realizado por professores Kaingang (T.I. Nonoai, junho/2016).

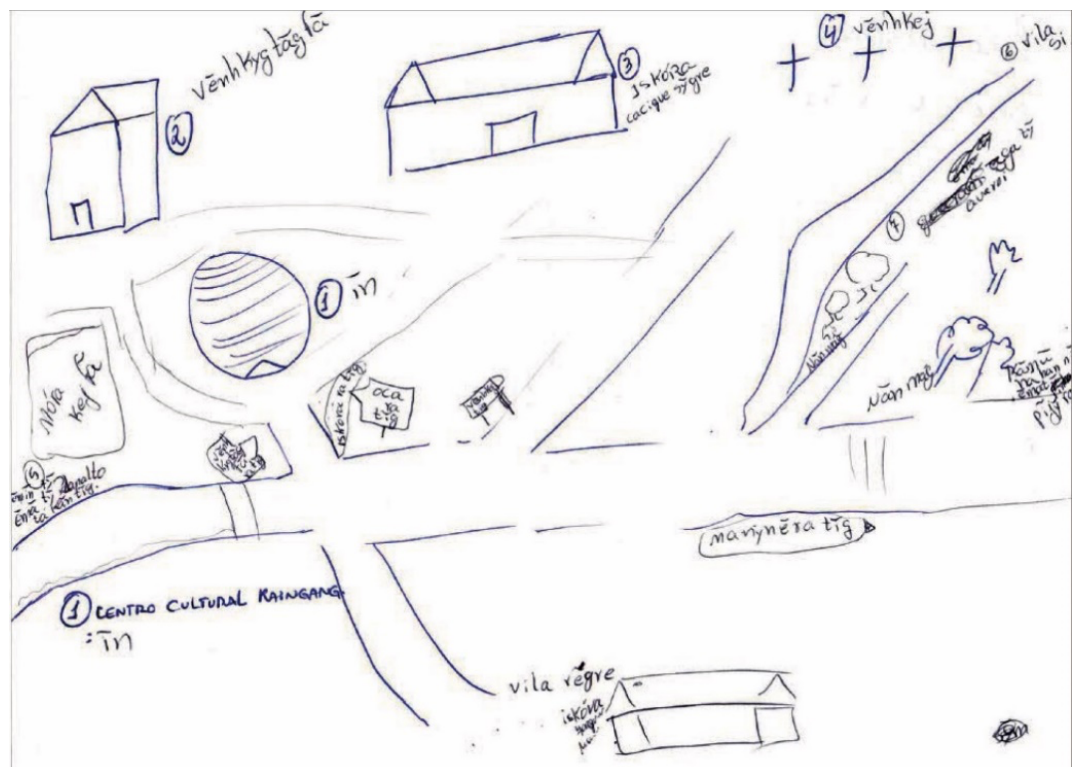

Figura 2. Mapa 2: Trabalho realizado por professores Kaingang (T.I. Nonoai, junho/2016).

O trabalho acima mostra a possibilidade do uso de placas que indiquem a localização de elementos-chave na aldeia: escolas, posto de saúde, centro cultural etc. Cabe ressaltar que essas placas não teriam, em princípio, a mesma utilidade que as placas similares do entorno. Todos os indivíduos se localizam muito bem sem elas. O objetivo principal seria dar alguma identidade linguística para a comunidade. Vale ressaltar que a comunidade é cortada por uma rodovia. Ao passar por ela, poderia acontecer de o não indígena perceber a natureza linguística peculiar que o trecho encerra. 


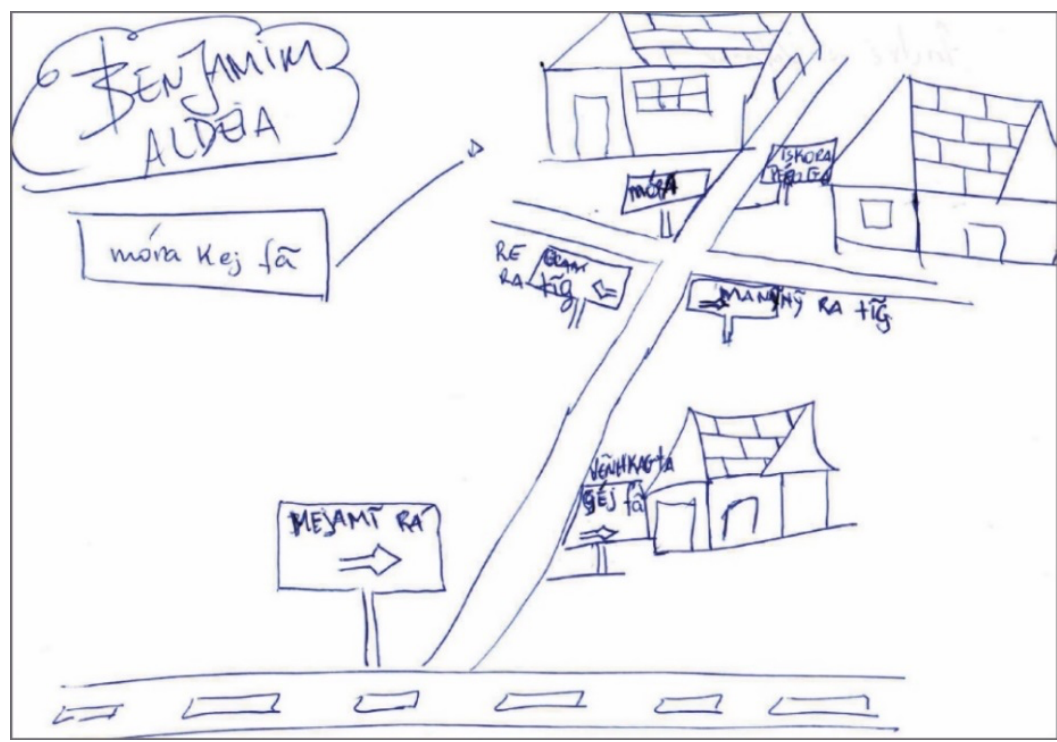

Figura 3. Mapa 3: Trabalho realizado por professores Kaingang (T.I. Nonoai, junho/2016).

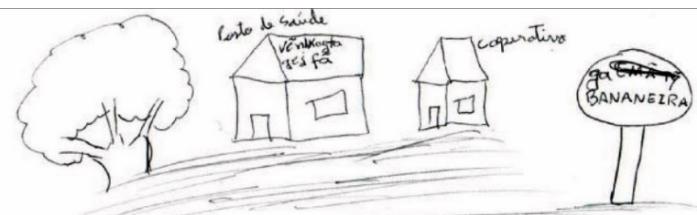

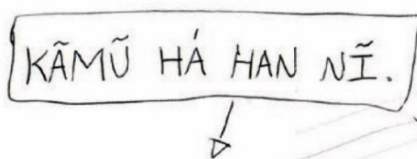
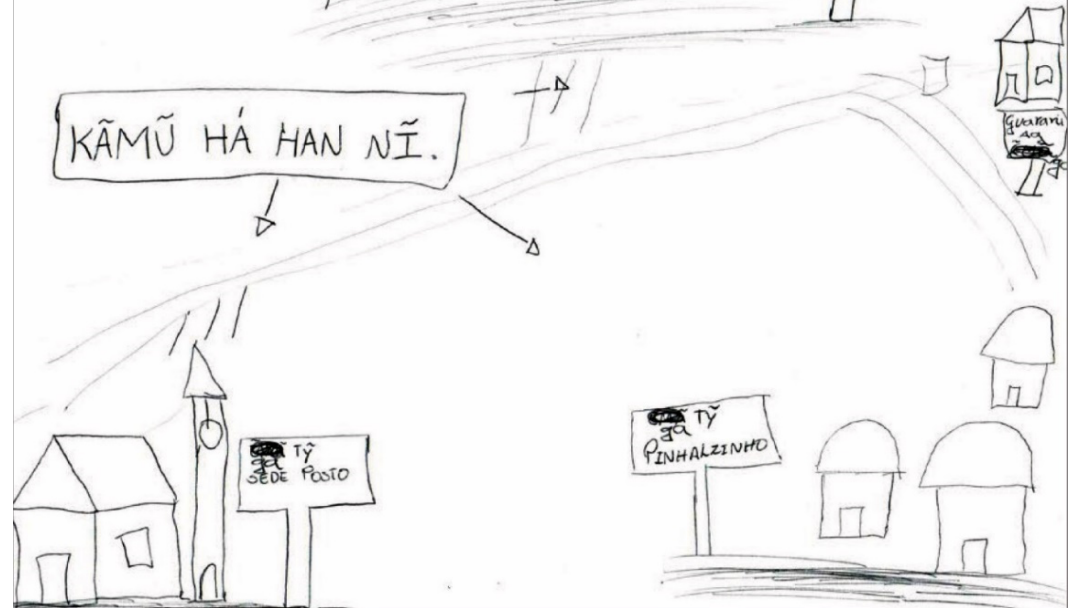

Figura 4. Mapa 4: Trabalho realizado por professores Kaingang (T.I. Nonoai, junho/2016). 


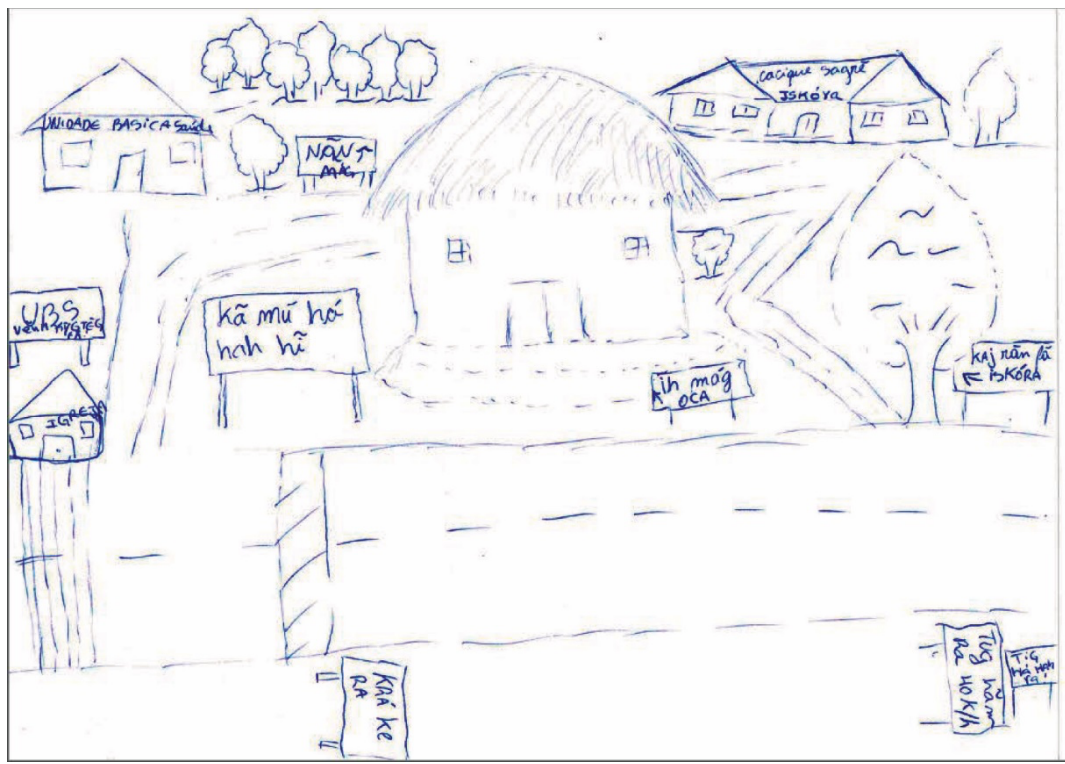

Figura 5. Mapa 5: Trabalho realizado por professores Kaingang (T.I. Nonoai, junho/2016).

Os mapas 3 e 5, além de placas indicadoras de localização, trazem placas que poderiam estampar também as instituições, como o posto de saúde e o Centro Cultural (que muitos Kaingang chamam de oca ou in mág - literalmente: 'casa grande'), por exemplo. Tanto as placas de localização como letreiros institucionais reafirmariam a identidade linguística da comunidade. Isso aumentaria a visibilidade da língua, oferecendo também referenciais para a língua escrita que iriam além de materiais didáticos.

\section{DISCUSSÃO}

Os resultados aqui apresentados nos mostram a necessidade de discussão para a adoção de padronização linguística para as placas. Essa padronização deve ser alcançada a partir de discussão entre os sujeitos envolvidos. Algumas das divergências estão na ortografia e pode ser devida a lapsos de escrita. Vejam-se, abaixo, três padrões distintos encontrados para figurar em placas para "Posto de Saúde" (que comporiam o que chamamos de "criações endógenas' (DAMULAKIS; SILVA, 2020), neologismos criados na língua para evitar o uso de empréstimos (a terceira conseguida através de comunicação pessoal): 


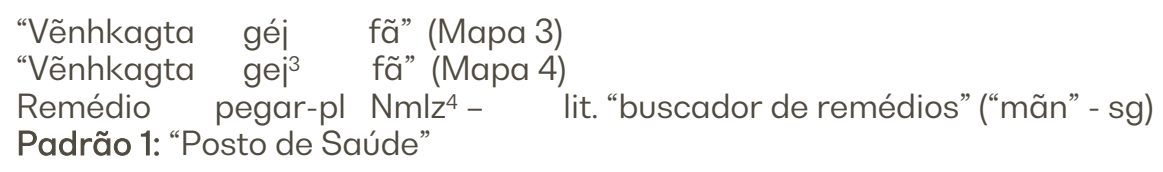

"Vẽnh kygtag fã" (Mapa 1)'

"Vẽnh kygtãg fã" (Mapa 3)

"Vẽnh kygtẽg 5 fã" (Mapa 5)

$3^{a}$ pess curar Nmlz- lit. "curador"

Padrão 2: "Posto de Saúde"

"Vẽnhkagta ju ĩn" (consulta informal; T.I. Nonoai; idosa de 50 anos)

Remédio de casa- lit. "casa dos remédios"

Padrão 3: "Posto de Saúde"

No padrão 1, encontramos a criação endógena na qual é descrita a função de distribuir remédios da instituição. No padrão 2, a função de curar se sobressai. O padrão 3 repete ressalta a mesma função vista no padrão 3. Essa diferença poderia ser explorada para pensar a diferença entre posto de saúde e hospital, por exemplo. Nos exemplos acima, as ocorrências tachadas foram descartadas por nós, por terem sido consideradas como erros de ortografia por outros professores Kaingang: é o caso de gejno padrão 1 e de kygtag no padrão 2.

Talvez o uso efetivo de placas na comunidade pudesse ser feito em padrão bilíngue, o que espelharia os usos linguísticos locais. A atividade, no entanto, não propunha essa possibilidade. Mesmo assim, em alguns casos, houve variações nas placas entre padrão bilíngue e padrão de sinônimos. Vejamos no detalhe os casos a seguir:

3 A palavra está tachada devido à grafia incorreta, conforme avaliado por professores Kaingang.

4 Nominalizador.

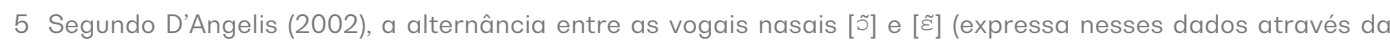
equivalente alternância ortográfica entre $\langle\tilde{a}\rangle \mathrm{e}\langle\mathrm{e} \otimes\rangle$, respectivamente) pode se referir a formas e dimensões do(s) referente(s) expresso(s) nos argumentos, no caso dos verbos. 


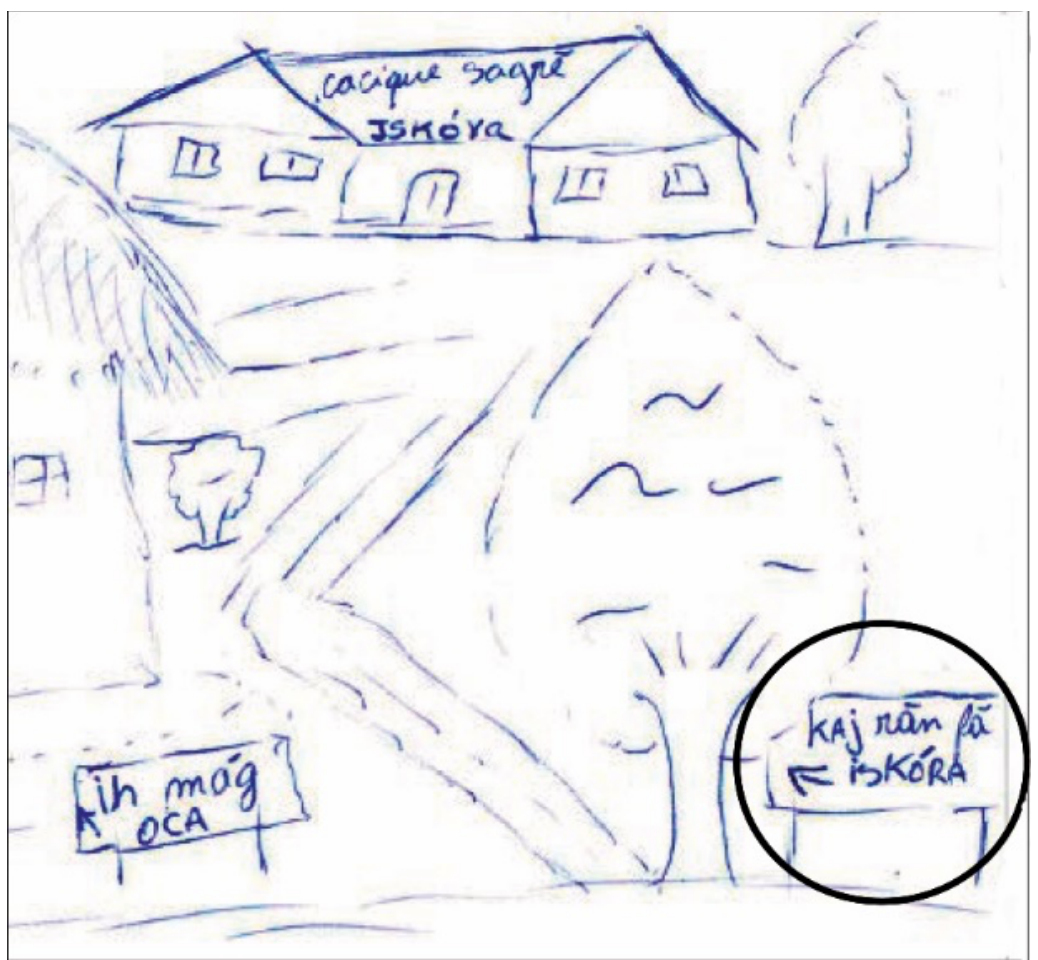

Figura 6. Mapa 5 (detalhe): trabalho realizado por professores Kaingang (T.I. Nonoai, junho/2016).

No detalhe do mapa 5, acima, encontramos, no círculo, duas designações para "escola": iskóra e kajrãn fã. A primeira é um empréstimo do português, com algumas adaptações fonológicas e ortográficas; a segunda constitui um exemplo de criação endógena: kajrãn "ensinar" + fã (nominalizador "algo feito para"), literalmente: "algo para ensinar", "ensinador"6. Em uma situação real, em uma confecção de placa os indígenas acabariam, muito provavelmente, optando por uma das duas.

6 Outros dois falantes, em consulta informal, relataram dois outros significados a essa criação endógena: "livro" e "professor". 


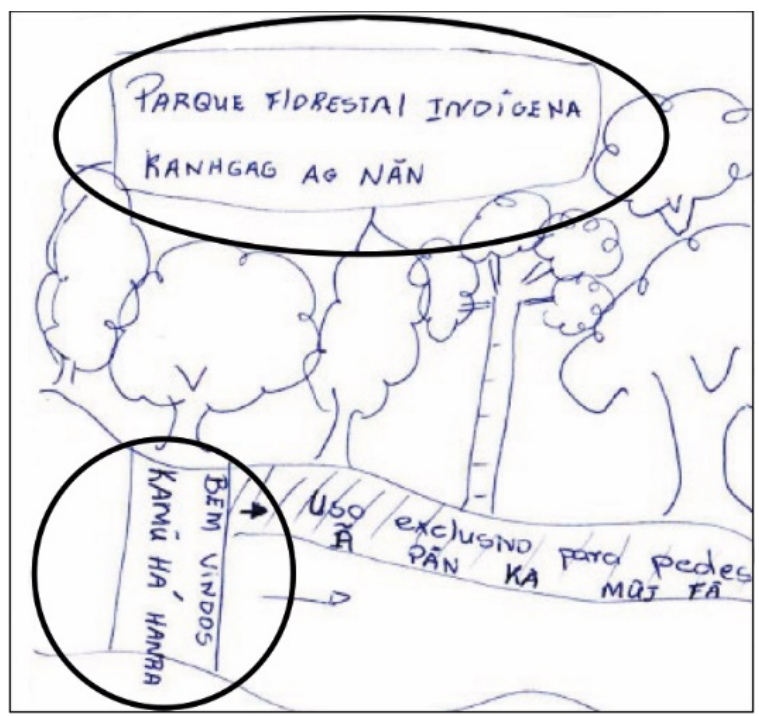

Figura 7. Mapa 1 (detalhe): trabalho realizado por professores Kaingang (T.I. Nonoai, junho/2016).

No detalhe do mapa 1, acima, vemos dois exemplos circulados de placas bilíngues. Embora não tivéssemos solicitado esse formato, um dos grupos o fez. A ordenação das línguas, em um caso de implementação de um sistema de placas (e em sendo essas placas bilíngues), poderia ser decidida pelos próprios indígenas.

\section{CONSIDERAÇÕES FINAIS}

O incremento da paisagem linguística com a escrita Kaingang pode ter como consequência o aumento do letramento em língua indígena. Efeito positivo da elaboração de placas viria a ser o fortalecimento da identidade da paisagem, o que igualaria a língua indígena ao português nesse sentido, uma vez que muitos indígenas circulam em ambientes, externos à aldeia, nos quais a paisagem linguística está dominada pelo português. Dessa forma, haveria um pareamento da língua Kaingang ao Português: a língua ancestral também merece ser alçada à 'permissão' de figurar em placas, por exemplo. As repercussões no imaginário e na identidade Kaingang poderiam ser positivas para o povo e para a língua.

Além disso, as placas e letreiros levam à circulação da língua em novos espaços de uso. Crianças teriam acesso à língua escrita fora do ambiente escolar. Uma consequência disso seria a padronização da escrita (ex. 'posto de saúde'), uma vez que a confecção das placas viria, necessariamente, da discussão sobre o que deveria figurar nessas placas. Isso aumentaria a reflexão sobre a língua, em sua versão escrita. Dessa forma, aumentar a visibilidade da língua pode apresentar repercussões positivas para a Escola Indígena, para o povo e para a própria língua. 


\section{AGRADECIMENTOS}

Agradeço, primordialmente, ao povo Kaingang pela acolhida durante o tempo em que estivemos na aldeia. Em especial, agradeço aos professores Kaingang participantes do curso, muito aderentes às atividades propostas. Sem eles, as ideias aqui expostas não teriam sido possíveis. À direção da Escola Estadual Indígena de Ensino Fundamental (EEIEF) Pẽró Ga, nossos mais sinceros agradecimentos pela infraestrutura fornecida durante o curso, assim como às direções das escolas dos demais participantes do curso (EIEM Cacique Sy® Gre e EEIEF Joaquim Gate®n Cassemiro), por incentivarem a participação de seus professores no curso.

Agradeço também a ajuda de Marcia (Kaingang) Nascimento e de Fabiana Alencar da Silva, por pensarem e coordenarem o curso junto comigo. A Wilmar D’Angelis, agradeço os comentários valiosos na primeira versão deste trabalho. Os erros e lacunas que persistiram são de minha inteira responsabilidade.

\section{REFERÊNCIAS}

DAMULAKIS, G. N.; SILVA, F. A. da. Notas sobre empréstimos linguísticos e criações endógenas no Kaingáng. In: SILVEIRA, M.; GUERRA, M. J. \& SANTOS, L (Orgs). Macro-Jê: língua, cultura e reflexões. Londrina: Eduel, 2020 .

D’ANGELIS, W. da R. Gênero em Kaingang? In: SANTOS, L.; PONTES, I. (orgs). Língua Jê: estudos vários. Londrina: Eduel, 2002, p. 215-242.

D'ANGELIS, W. da R. Como nasce e por onde se desenvolve uma tradição escrita em sociedades de tradição oral? Campinas: Editora Curt Nimuendajú, 2007.

D’ANGELIS, W. da R. Aprisionando sonhos: a educação escolar indígena no Brasil. Campinas: Editora Curt Niemuendajú, 2012.

FRANCHETTO. B. A guerra dos alfabetos: os povos indígenas na fronteira entre o oral e o escrito. Mana, v. 14, n. 1,2008

KLEIMAN, Angela. Os Estudos de Letramento e a formação do professor de língua materna. Linguagem em (Dis)curso - LemD, v. 8, n. 3, p. 487-517, set./dez. 2008.

LANDRY, R.; BOURHIS, R. Linguistic Landscape and Ethnolinguistic Vitality - An Empirical Study. Journal of Language and Social Psychology, 16, 23-49, 1997.

SILVA, F. A.; DAMULAKIS, G. N. Lexical Amplification in Kaingang Stimulated by Contact with Brazilian Portuguese. In: Kawsaxkuna: The University of Toronto Journal of Latin American Studies. v. 1. 2017, 16-23.

SOARES, Magda. Letramento: Um tema em três gêneros. Belo Horizonte: Autêntica, 1998. 